\title{
Islamitische scholen dragen bij aan integratie
}

\author{
Marietje Beemsterboer
}

\begin{abstract}
Dertig jaar geleden werden de eerste islamitische basisscholen gesticht en sindsdien liggen de scholen van tijd tot tijd onder vuur. Critici vrezen dat de religieuze segregatie de sociale integratie van leerlingen belemmert. Het promotieonderzoek van Marietje Beemsterboer concludeerde het tegendeel. In dit artikel wordt met praktijkvoorbeelden uiteengezet hoe islamitische basisscholen bijdragen aan de integratie van moslims in de Nederlandse maatschappij. In de conclusie wordt de vraag gesteld op welke manier bijzondere basisscholen bijdragen aan emancipatie en integratie.
\end{abstract}

\section{Inleiding}

Over artikel 23 van de Grondwet lopen de meningen principieel uiteen. Voorstanders prijzen de Nederlandse keuzevrijheid in het onderwijs en wijzen op de mogelijkheden een school te kiezen die aansluit op de thuissituatie. Tegenstanders wijzen op de overheidsplicht om neutraal en objectief onderwijs te verzorgen en pleiten voor één openbare school voor kinderen uit alle sociale klassen en met allerlei religieuze, etnische en sociaaleconomische achtergronden. Van tijd tot tijd wordt in de politiek gezocht naar mogelijkheden om artikel 23 zodanig te hervormen dat een divers onderwijslandschap blijft bestaan en tegelijkertijd (religieuze) segregatie wordt teruggedrongen. Een voorbeeld hiervan is de 'richtingvrije planning' uit het advies van de Onderwijsraad uit 2012, ${ }^{1}$ die is verwerkt in het wetsvoorstel 'Meer Ruimte voor Nieuwe Scholen' dat op dit moment voorligt bij de Tweede Kamer en naar verwachting op 1 augustus 2019 in werking treedt. Ook kondigde Lodewijk Asscher eind 2018 aan een initiatiefwet in te dienen die het bijzondere scholen onmogelijk maakt leerlingen te weigeren vanwege een andere (religieuze) overtuiging. ${ }^{2}$

De wens om religieuze segregatie terug te dringen is gebaseerd op de aanname dat bijzonder confessionele basisscholen sociale integratie van leerlingen tegenwerken. Dit beeld overheerst zeker bij islamitisch onderwijs. Deze aanname is eerder in dit tijdschrift ter discussie gesteld en wordt ook in mijn proefschrift ontkracht. ${ }^{3}$ Uit mijn promotieonderzoek op islamitische basisscholen blijkt namelijk dat islamitische scholen in veel gevallen juist bijdragen aan de sociale integratie van leerlingen. 


\section{Islamitisch onderwijs in Nederland}

\section{Jaren tachtig}

De eerste islamitische basisscholen werden zo'n dertig jaar geleden, aan het eind van de jaren tachtig, opgericht. Eind jaren zeventig en in de jaren tachtig nam het aantal moslimkinderen in Nederland snel toe. Aanvankelijk volgden deze kinderen onderwijs op openbare, katholieke en protestants-christelijke basisscholen. Maar de vrees dat kinderen zouden vervreemden van de islamitische cultuur en onvrede over het openbaar en christelijk onderwijs leidde tot een behoefte aan bijzondere scholen op islamitische grondslag. Onder hoogopgeleide migrantenouders bestond ook het vermoeden dat hun kinderen op openbare en christelijke scholen werden benadeeld door een laag verwachtingspatroon onder leerkrachten. ${ }^{4}$ Onvrede was er ook over het verschil in ideeën over opvoeding tussen de Nederlandse scholen en de migrantenouders. Op Nederlandse scholen werden via spelend en ontdekkend leren assertiviteit en mondigheid bevorderd, terwijl onder de eerstegeneratiemigranten morele ontwikkeling, conformiteit en trouw aan (religieuze) autoriteit centraal stonden. ${ }^{5}$ In veel gezinnen leidde het verschil in opvoedingsdoelen tussen de situatie thuis en die op school tot een gezagscrisis. Migrantenouders wilden dat scholen meer aandacht hadden voor de overdracht van de normen en waarden die in de thuissituatie werden aangemoedigd. ${ }^{6}$

De eerste initiatieven om islamitische scholen te stichten waren niet direct succesvol. Bij de initiatiefnemers schortte het aanvankelijk aan kennis van de Nederlandse taal en het Nederlandse onderwijssysteem, en er was ook een gebrek aan medewerking van gemeenten en overige betrokken instanties. ${ }^{7}$ Aan het eind van de jaren tachtig steeg de organisatiegraad van de islamitische gemeenschap en ontstond er meer toegang tot externe advisering. Dit resulteerde onder meer in de oprichting van de eerste twee islamitische basisscholen in $1988 .^{8}$

\section{Jaren negentig}

Zoals zichtbaar wordt in tabel 1 groeide het aantal islamitische basisscholen vooral de eerste jaren sterk. Tegelijkertijd veranderde het maatschappelijke

4 W.A. Shadid \& P.S. van Koningsveld, 'Islamic Primary Schools', in: Islam in Dutch society: Current developments and future prospects, Kampen 1992, p. 107-123.

5 T. Pels, M. Distelbrink \& L. Postma, Opvoeding in de migratiecontext, Utrecht 2009.

6 E. Dumasy, Kwaliteitsdilemma's van islamitische scholen, Amsterdam 2008, p. 70-72; P. Schreiner, 'Religious Education in the European Context', Hungarian Educational Research Journal, 2013, p. 5-15; S. van de Wetering \& A. Karagül, Zoek kennis van de wieg tot het graf, Antwerpen 2013, p. 113-116.

7 N. Landman, Van mat tot minaret, Amsterdam 1992, p. 261; J. Rath e.a., Nederland en zijn islam, Amsterdam 1996, p. 66-74; W.A. Shadid \& P.S. van Koningsveld, Islam in Nederland en België. Religieuze institutionalisering in twee landen met een gemeenschappelijke voorgeschiedenis, Leuven 2008; M. Maussen, Ruimte voor de islam? Stedelijk beleid, voorzieningen, organisaties, Apeldoorn 2006, p. 187; W.A. Shadid \& P.S. van Koningsveld, Moslims in Nederland, Houten 1997, p. 161-167.

8 Shadid \& Van Koningsveld 2008, p. 247-258; Maussen 2006, p. 187; Van de Wetering \& Karagül 2013, p. 28, 32-33; Rath e.a. 1996, p. 55-64. 


\section{Tabel 1 Groei van het aantal islamitische basisscholen}

\begin{tabular}{llll}
\hline Lustrum & $\begin{array}{l}\text { Aantal scholen } \\
\text { Gesticht }\end{array}$ & Gesloten & Totaal \\
\hline $1988-1992$ & 27 & 0 & 27 \\
$1993-1997$ & 4 & 1 & 30 \\
$1998-2002$ & 8 & 2 & 36 \\
$2003-2007$ & 13 & 6 & 43 \\
$2008-2012$ & 3 & 1 & 45 \\
$2013-2018$ & 7 & 0 & 52 \\
\hline
\end{tabular}

discours over integratie: waar in de jaren tachtig nog werd gepleit voor 'integratie met behoud van eigen identiteit', werd diezelfde 'eigen identiteit' van met name moslimmigranten vanaf de jaren negentig als problematisch ervaren. ${ }^{9}$

Hoewel islamitische scholen in de jaren negentig slechts $0,3 \%$ van het totale aantal basisscholen vormden, waren zij wel aanleiding voor politieke discussie. Toenmalig VVD-leider Frits Bolkestein sprak over de onwenselijkheid van een 'islamitische zuil' en benoemde islamitische scholen als een onwenselijk voorbeeld van een gescheiden samenleving. ${ }^{10}$ De politieke en maatschappelijke discussie zette de islamitische basisscholen in Nederland onder druk. Het aantal nieuwe gestichte scholen stagneerde, stichtingsinitiatieven stuitten overwegendop lokale weerstand en er werd met argusogen gekeken naar de kwaliteit en het functioneren van de scholen.

Het jaar 2000 en later

Het politieke en maatschappelijke debat verhardde na de millenniumwisseling. Tegen de achtergrond van de aanslagen van 11 september 2001 in New York en Washington, de moord op Pim Fortuyn in 2002, de aanslagen in Madrid (2004) en Londen (2005) en de moord op Theo van Gogh in 2004 groeide de politieke en maatschappelijke weerstand tegen moslims. ${ }^{11}$

In 2002 publiceerden de toenmalige Binnenlandse Veiligheidsdienst (BVD) en de Onderwijsinspectie rapporten over het islamitisch onderwijs. De strekking van beide rapporten was dat islamitisch basisonderwijs over het algemeen geen belemmering vormde voor de Nederlandse democratie. Maar er werden wél kritische kanttekeningen geplaatst bij het functioneren van enkele scholen. ${ }^{12}$ Ondanks de gematigd positieve strekking van de rapporten bleef er politiek en

9 H. Entzinger \& E. Dourelijn, De lat steeds hoger, Assen 2008, p. 102.

10 F. Bolkestein, 'Integratie van minderheden moet met lef worden aangepakt', de Volkskrant 12 september 1991.

11 H. Vermeulen \& R. Penninx, Immigrant integration: the Dutch case, Amsterdam 2000, p. 96; Nationaal Archief, Een samenleving in beweging. Nederland tussen 1976 en 2005 in 200 trends en 100 hotspots, Den Haag 2016, p. 989-990.

12 Binnenlandse Veiligheidsdienst, De democratische rechtsorde en islamitisch onderwijs. Buitenlandse inmenging en anti-integratieve tendensen, Den Haag 2002; Inspectie van het Onderwijs, Islamitische scholen en sociale cohesie, Den Haag 2002. 
maatschappelijke wantrouwen richting islamitisch onderwijs bestaan en werd aangedrongen op meer onderzoek. ${ }^{13}$

In 2003 constateerde de Inspectie van het Onderwijs dat op islamitische basisscholen niet werd aangezet tot intolerantie of haat. De inspectie stelde dat het onderwijs op islamitische basisscholen niet verschilde van vergelijkbare scholen. Maar er waren ook kritische kanttekeningen: de pedagogisch-didactische kwaliteit van de godsdienstlessen liet te wensen over en islamitische scholen waren bestuurlijk kwetsbaar. ${ }^{14}$

Vijf jaar later, in 2008, verscheen er opnieuw een rapport van de Inspectie van het Onderwijs, ditmaal specifiek gewijd aan de bestuurlijke praktijken in het islamitisch onderwijs. Het oordeel was matig negatief: de Inspectie oordeelde dat de bestuurlijke kwaliteit van islamitische basisscholen relatief vaak achterbleef bij die van andere Nederlandse basisscholen. Verbetering was volgens het onderzoek noodzakelijk om een stabiele bestuurlijke omgeving te kunnen scheppen. ${ }^{15}$

Er was destijds terechte reden tot zorg. Tussen 2005 en 2010 werd ongeveer $40 \%$ van de islamitische scholen als 'zwak' of 'zeer zwak' beoordeeld. In 2009 werd een islamitische basisschool in Amsterdam tijdelijk gekort op de subsidie omdat de school - ook na een traject van intensief toezicht - in de ogen van de Inspectie actief burgerschap en sociale integratie bij de leerlingen onvoldoende bevorderde. ${ }^{16}$ Hoewel de onderzoeksrapporten overwegend concludeerden dat islamitisch onderwijs geen belemmering vormde voor integratie, werden in de politieke discussie vaak de kritische kanttekeningen uitvergroot en de hoofdlijnen van de onderzoeken genegeerd. ${ }^{17}$

Dit paste ook bij het dominante beeld in de beginjaren van de 21ste eeuw dat de islam de integratie in de westerse samenleving belemmerde.

\section{Huidige situatie}

In de afgelopen jaren hebben islamitische basisscholen zich verder ontwikkeld: hun aantal is toegenomen en de bestuurlijke organisatievorm is vaak veranderd, schoolbesturen hebben zich onder invloed van fusies geprofessionaliseerd, en ook de kwaliteit van het onderwijs is enorm toegenomen. Nederland kent op dit moment 49 islamitische basisscholen. Het islamitisch basisonderwijs vormt daarmee $0,7 \%$ van het totale aantal basisscholen in Nederland.

Maar de zorgen over islamitische basisscholen bestaan nog steeds en worden gevoed door berichtgeving over een minderheid van islamitische basisscholen met een streng islamitische identiteit.

De vraag blijft of het mogelijk is dat scholen de islamitische identiteit van leerlingen kunnen versterken én bijdragen aan de integratie van diezelfde leerlingen in de Nederlandse samenleving.

16 Inspectie van het Onderwijs, Rapport van bevindingen. Onderzoek bij IBS As-Siddieq, Haarlem 2009. 


\section{Onderlinge diversiteit}

Tussen 2013 en 2014 nam ik in het kader van mijn promotieonderzoek 75 interviews af met directeuren, godsdienstleerkrachten en groepsleerkrachten op 19 islamitische scholen. Deze scholen waren geselecteerd op hun ligging, grootte en oprichtingsjaar en zij vertegenwoordigden verschillende schoolbesturen. De conclusies en voorbeelden die in dit artikel worden behandeld, gaan terug op dat onderzoek, waarnaar ik hier voor meer voorbeelden en context graag eenmalig verwijs. ${ }^{18}$

De 49 islamitische basisscholen in Nederland verschillen sterk van elkaar. Hoewel in de praktijk bijna alle leerlingen moslim zijn, is de schoolpopulatie verre van homogeen. Integendeel, de leerlingenpopulatie verschilt naar etniciteit en, tot op zekere hoogte, ook naar sociale klasse. Er zijn kinderen van eerste-, tweede- en derdegeneratiemigranten, kinderen en ouders voelen verwantschap met verschillende wetscholen en stromingen in de islam. Ten slotte verschilt ook de waarde die door gezinnen en kinderen wordt toegekend aan de islam in het dagelijks leven. Dit maakt de schoolpopulatie op islamitische basisscholen heel divers.

Wanneer directeuren en leerkrachten wordt gevraagd hoe zij omgaan met de onderlinge diversiteit, geven zij aan 'de basis' te volgen, waarin alle moslims zich kunnen vinden, en te zoeken naar de gemene deler. Op alle islamitische basisscholen krijgt de specifieke religieuze identiteit vorm door het Offerfeest en Suikerfeest te vieren en wordt vanaf de bovenbouw één keer per dag met de kinderen het gebed uitgevoerd. De kinderen zijn in plaats van op woensdagmiddag op vrijdagmiddag vrij, zodat zij eventueel het middaggebed kunnen bijwonen. Op de meeste scholen geldt voor personeel en leerlingen een kledingvoorschrift, bijvoorbeeld dat vrouwen kleding moeten dragen die 'de lichaamsvormen verhult'.

In de dagelijkse praktijk op islamitische scholen zijn er echter ook verschillen, die teruggaan op onderlinge verschillen tussen de bestuursleden, directieleden, ouders en leraren. Ouders, leerkrachten en directieleden delen echter de verwachting dat de islamitische basisscholen beter dan andere scholen aansluiten op de specifieke thuissituatie van leerlingen. Mede omdat er allerlei verschillen en interpretaties over de geloofsbeleving zijn, ontstaat er op de scholen een dialoog tussen ouders, leerkrachten en de schooldirectie over welke vorm van de islam de school volgt.

Een voorbeeld van een twistpunt is mawlid, de geboorte- en sterfdag van de Profeet. Deze dag wordt door bepaalde groepen moslims feestelijk gevierd, terwijl andere groepen de viering van deze dag afkeuren als een niet oorspronkelijk islamitisch feest maar een latere menselijke interventie. Een vergelijkbare verdeeldheid is te vinden rond het afbeelden van levende wezens, waardoor de ene leerling zonder gewetenswroeging een poppetje tekent en poseert op de schoolfoto, terwijl de andere leerling dat als haram beschouwt en van zijn ouders niet op de schoolfoto mag. 
Islamitische scholen hebben te maken met dit soort tegenstellingen en deze worden op school bediscussieerd. Vervolgens maakt een school een eigen afweging en krijgt zo zijn eigen identiteit.

\section{Van dialoog naar schoolidentiteit}

Om te illustreren hoe een interne dialoog vorm krijgt wordt hierna ingegaan op muzikale vorming en de Koningsspelen. Rond muziek en muzikale vorming bestaat onder moslims vaak een 'theologische' discussie. In de Koran wordt niet duidelijk over muziek gesproken en in hadith-literatuur zijn zowel fragmenten te vinden waaruit zou blijken dat Mohammed muziek meed als fragmenten waaruit blijkt dat hij muziek juist toestond. ${ }^{19}$ Deze theologische discussie vertaalt zich in een diversiteit aan posities onder moslims: er zijn moslims te vinden die thuis of in de auto naar de radio luisteren, maar ook moslims die muziek vermijden en weglopen bij gelegenheden waar muziek wordt gedraaid. Het volgende citaat illustreert hoever islamitische basisscholen in die invulling van elkaar kunnen verschillen:

'Tijdens één van de optredens [waarbij verschillende islamitische scholen verenigd waren] pakte een leerling een elektrische gitaar en die ging zitten spelen en toen stonden er dus echt mensen op en die liepen weg. Die hadden echt zoiets van: dit kan niet. (...) [Bij soortgelijke gelegenheden, hebben we $\mathrm{nu}$ ] gezegd dat er geen muziekinstrumenten gebruikt mogen worden. Anders zouden we andere mensen buitensluiten. (...) Ook bijvoorbeeld met foto's bij de landelijke kennis quiz: we hebben een locatie waarbij ook een balkon is, dus dan kunnen de mensen die niet op de foto willen even op het balkon staan.'

De spanning rond muziek wordt op de meeste scholen opgelost door de inhoud van de muzieklessen enigszins aan te passen. Er zijn scholen die niet met melodie-instrumenten werken omdat dat gevoelig ligt ${ }^{20}$ en die vooral gebruikmaken van a-capellazang, ritme-instrumenten en religieuze lofliederen (anashied). Ook zijn er scholen die de gevoeligheid opzoeken en kinderen bewust wél in aanraking brengen met melodie-instrumenten zoals piano en gitaar, en met westerse muziek (klassiek, pop, blues enzovoort). Deze scholen vinden bijvoorbeeld dat leerlingen kennis moeten maken met het westerse cultureel erfgoed en dat kinderen verschillende muziekinstrumenten moeten kennen.

19 N. ter Laan, Dissonant voices. Islam-inspired Music in Morocco and the Politics of Religious Sentiments, Nijmegen 2016, p. 7-8; J. Otterbeck \& A. Ackfeldt, 'Music and Islam', Contemporary Islam 2012, p. 227-233; J. Otterbeck, 'Music as a useless activity: conservative interpretations of music in Islam', Zed 2004, p. 11-16; I. Bedford, 'The Interdiction of Music in Islam', Australian Journal of Anthropology 2001, p. 1.

20 L. Lamya' al-Faruqi, 'The shari'ah on music and musicians', in: I. Raji Al-Faruqi, Islamic Thought and Culture, Hendon 1989, p. 33-53; J.M. Halstead, 'Muslims and sex education', Journal of Moral Education 1997, p. 317-330; Bedford 2001; Otterbeck 2004; Otterbeck \& Ackfeldt 2012. 
Een ander voorbeeld van een interne dialoog op een islamitische school is de discussie rond de Koningsspelen. De Koningsspelen, een landelijke sportdag voor Nederlandse basisscholen, vinden sinds 2013 jaarlijks plaats en waren op veel islamitische basisscholen aanleiding voor intern overleg. Vóór 2013 gold Koninginnedag als vrije dag en konden islamitische basisscholen volstaan met een les over de Nederlandse feestdag. Dit veranderde met de invoering van de Koningsspelen als landelijke sportdag voor scholen. Tijdens de Koningsspelen komen drie verschillende spanningsgebieden bij elkaar. Allereerst ligt het organiseren van een dag in naam van of ter ere van de Nederlandse koning voor sommige ouders gevoelig vanwege de verering van een persoon, en voor andere ouders ook vanwege de loyaliteit die zij voelen richting een staatshoofd die is verbonden aan hun land van herkomst. Ten tweede zijn de Koningsspelen verbonden aan de verjaardag van de koning, een dag die binnen de islamitische traditie eerder een dag van bescheiden bezinning is dan een feestdag. Ten slotte is het karakter van een dag waarop jongens en meisjes gemengd sporten en dansen voor sommige ouders problematisch.

Deze drie spanningsgebieden vormen een aanleiding voor directie, leerkrachten en ouders die bij islamitische scholen betrokken zijn om met elkaar te spreken over de invulling van de Koningsspelen, op een manier die kinderen deelgenoot maakt van een landelijke viering voor alle Nederlandse kinderen, die past bij de identiteit van de school en die in ieder geval de meerderheid van de ouders tevreden stemt. Een van de directeuren vertelde hierover:

Directeur: '[Ouders] hebben moeite met het feit dat [de Koningsspelen naar aanleiding van] een verjaardag is. [Dat geldt voor] sommigen, de helft. En anderen hebben er moeite mee omdat we koningsgezind lijken. Maar je bent in Nederland. (...) Dit zijn ouders die zeggen dat de enige aan wie je verantwoording moet afleggen Allah is. Dat staat ze tegen. Je respecteert dat [als directeur]. Het stukje over de verjaardag van de koning vieren, heb ik wel serieus genomen omdat dat iets [een standpunt] is wat de helft van de [islamitische] stromingen wel erkent. Ik moet dat [dan] bespreken binnen de identiteitscommissie, ongeacht wat ik daar zelf van vind. (...)'

Interviewer: 'En hoeveel procent van de ouders hebben moeite met de Koningsspelen?'

Directeur: ' 2 van de 250, en moeite met verjaardagen: 10 van de 250. Maar binnen de identiteitscommissie, die alle scholen vertegenwoordigt, is het echt 50/50 geweest.'

De discussies over 'spanningsgebieden' leiden soms tot relatief kleine aanpassingen in het onderwijsprogramma, bijvoorbeeld rond de keuze van de liedjes tijdens de muziekles en van de instrumenten die de school aanschaft. Vaak leidt het ertoe dat een school ouders informeert over de wijze waarop op school invulling wordt gegeven aan 'spannende' lesinhoud en waarom de school dergelijk onderwijs noodzakelijk acht. 


\section{Groeiende ruimte voor maatschappelijke context}

Op alle onderzochte islamitische scholen krijgt de maatschappelijke context van de school in toenemende mate gewicht in het schoolbeleid en de dagelijkse praktijk. Als de huidige ontwikkeling zich doorzet, betekent dat, vertaald naar het praktijkvoorbeeld van muzikale vorming, dat op steeds meer islamitische basisscholen kinderen bedachtzaam maar doelbewust in aanraking brengen met westerse muziek.

Waar het verplichten van de hoofddoek dertig jaar geleden vaak voor alle vrouwelijke leerkrachten - ook voor leerkrachten die zelf geen moslim waren - de norm was, staat dat iedereen tegenwoordig op steeds meer scholen vrij en werken er ook moslima's zonder hoofddoek. Ook zijn er meer scholen die bewust zoeken naar leerkrachten met een Nederlandse achtergrond. De overheid heeft scholen de afgelopen jaren in toenemende mate verplicht om bij te dragen aan 'actief burgerschap en sociale integratie', maar op veel islamitische basisscholen wordt dit streven ook gevoed van binnenuit. In de opvoedingsidealen van moslimouders is de afgelopen jaren meer aandacht gekomen voor assertiviteit en autonomie, moslimkinderen kregen meer bewegingsvrijheid en de opvoeding vindt in toenemende mate plaats in een meer open communicatie. ${ }^{21}$ Met de verandering van de opvoedingsidealen verandert ook de verwachting die ouders hebben ten aanzien van een basisschool.

Parallel aan de veranderende opvoedingsidealen van ouders verschoof op veel islamitische scholen het accent van islamitische uitingsvormen naar een verinnerlijking van islamitische waarden. Het dragen van de hoofddoek is op veel scholen een vrije keuze, en in het godsdienstonderwijs is nu minder nadruk op het memoriseren van een groot aantal Koranverzen en meer aandacht voor kennis van de Koran en het vermogen de betekenis te vertalen naar het dagelijks leven als goed mens.

\section{Moslimkinderen en integratie}

In tegenstelling tot de algemene opinie over islamitische basisscholen concludeer ik in mijn onderzoek dat de scholen juist bijdragen aan de sociale integratie van leerlingen in de samenleving. Een reden hiervoor is dat islamitische basisscholen ouders en kinderen een gevoel van geborgenheid bieden; de islamitische identiteit maakt dat ouders en kinderen zich niet hoeven te verontschuldigen vanwege het feit dat zij bijvoorbeeld thuis geen Sinterklaas vieren, een hoofddoek dragen of

21 F. Bucx e.a., Opvoeden in niet-westerse migrantengezinnen: een terugblik en verkenning, Den Haag 2015, p. 53-54; T. Pels, 'Oratie: Opvoeden in de multi-etnische stad', Pedagogiek 2010, p. 211-235; A. van Keulen \& A. van Beurden, Van alles wat meenemen: diversiteit in opvoedingsstijlen in Nederland, Bussum 2010, p. 34; Pels, Distelbrink \& Postma 2009, p. 20; Entzinger \& Dourelijn 2008, p. 56-57, p. 139; M. de Koning, Zoeken naar een 'zuivere' islam, Amsterdam 2008, p. 179; L. Eldering, Cultuur en opvoeding: interculturele pedagogiek vanuit ecologisch perspectief, Rotterdam 2006, p. 236-237; T. Pels, 'De generatiekloof in allochtone gezinnen: mythe of werkelijkheid?', Pedagogiek 2000, p. 1-9. 
liever geen hand geven. Ook worden op een islamitische school geen traktaties met varkensvlees of (varkens)gelatine aangeboden. Alle leerkrachten hebben enige basiskennis van de islam, en de religieuze identiteit van de school maakt dat leerkrachten sensitief zijn voor eventuele spanningsgebieden tussen de thuiscultuur en de norm op school. Het gevoel van geborgenheid vormt de basis voor een hechte schoolgemeenschap, die de betrokkenheid bij het onderwijs vergroot. ${ }^{22}$ Het gevoel van ouders en leerlingen dat ze veilig zijn en begrepen worden vergroot het zelfvertrouwen van leerlingen, draagt bij aan onderwijsprestaties en werkt positief voor de integratie bij het bespreken van gevoelige onderwerpen. ${ }^{23}$

Islamitische scholen kúnnen vanuit het gevoel van geborgenheid niet alleen bijdragen aan integratie, maar doen dat ook actief. Het gebeurt misschien niet op alle islamitische scholen, maar uit mijn promotieonderzoek kwamen verschillende voorbeelden naar voren van momenten waarop op islamitische basisscholen bewust werd bijgedragen aan de integratie van moslims in de samenleving. Dit betrof vaak momenten waarop de school een stapje verder richting de maatschappelijke context zette dan thuis zou gebeuren. Juist de geborgenheid van de school zorgde er in dergelijke situaties voor dat de boodschap landde bij de kinderen. Een concreet voorbeeld is gerelateerd aan seksuele diversiteit, sinds 2012 een verplicht onderdeel van de curricula op alle Nederlandse basisscholen. ${ }^{24}$ Wanneer een leerkracht op een openbare of katholieke basisschool in de klas vertelt dat homoseksualiteit in Nederland geaccepteerd dient te worden, is de kans groot dat een islamitische leerling zich niet aangesproken zal voelen. Een moslimleerling die thuis of in de moskee een ander geluid te horen krijgt, zou kunnen denken: juf weet het misschien niet, maar deze boodschap geldt niet voor mij. Als dezelfde boodschap echter door de godsdienstleerkracht op een islamitische school wordt gegeven, weten de kinderen dat de boodschap speciaal voor hen is bedoeld. De godsdienstleerkracht geldt als religieuze autoriteit in de ogen van de kinderen en hun ouders.

Op eenzelfde manier worden op islamitische scholen bijvoorbeeld gesprekken gevoerd over de verhouding tot niet-moslims, seksuele voorlichting in het algemeen en het schudden van handen tijdens een sollicitatiegesprek. Wanneer scholen, vanuit de geborgenheid die zij bieden, bewust onderwerpen aansnijden die vanwege de religieuze identiteit van de leerlingen thuis gevoelig liggen of taboe zijn, kan religieuze segregatie dus wel degelijk bijdragen aan integratie.

\section{Integratie op niet-islamitische basisscholen}

Aangezien islamitische basisscholen slechts $0,8 \%$ van het totale aantal scholen in Nederland vormen, volgt veruit het grootste deel van de moslimleerlingen onderweinig achterstandsleerlingen, Nijmegen 2007.

23 M. Fricker, Epistemic injustice: power and the ethics of knowing, Oxford 2009.

24 J. Bron e.a., Seksualiteit en seksuele diversiteit in de kerndoelen. Een leerplanvoorstel en voorbeeldlesmateriaal, Enschede 2015, p. 5. 
wijs op openbare, katholieke en protestants-christelijke scholen. Op die scholen is het aannemelijk dat de moslimleerlingen ook met andersgelovige leerlingen in contact komen. Is die situatie niet wenselijker voor de sociale integratie? Niet per definitie, wijst onderzoek uit. Onbevangen ontmoeten is op de meeste scholen namelijk niet aan de orde. Integendeel, net als in de rest van de samenleving ${ }^{25}$ worden allochtone leerlingen, en in het bijzonder islamitische leerlingen, gestigmatiseerd. ${ }^{26}$ De schadelijke gevolgen van het internaliseren van de overtuigingen die samenhangen met stigmatisering zijn ingrijpend. Het leidt tot een lager zelfbeeld, lagere onderwijsprestaties en uiteindelijk tot minder sociale kansen en grotere kans op maatschappelijk falen. ${ }^{27}$

Tijdens mijn promotieonderzoek hoorde ik veel verhalen over kinderen die op latere leeftijd instroomden in het islamitisch onderwijs, omdat zij zich op een niet-islamitische school 'anders' voelden of om het anders-zijn werden gepest. De volgende citaten zijn daarvan een voorbeeld:

'Ik heb wel vaker nieuwe kinderen gehad in groep 6. (...) Daar heb ik ook vaak kinderen gehad die echt zoiets hadden van "hier ben je niet anders, hier word je niet gepest omdat je een hoofddoek hebt, omdat je Marokkaans bent". Je hoeft er ook niet achteraan te zitten omdat je Marokkaans bent of zo.'

'[Toen mijn zoon in groep 6 op een andere school kwam] was net dat lied van kutmarokkaan. Het kwam net uit. En hij hoefde maar iets te doen en dan begonnen ze [in de klas] dat lied te zingen.'

Vanzelfsprekend zijn er ook tal van voorbeelden te vinden van moslimkinderen die op een niet-islamitische school goed in hun vel zitten. Deze onderzoeken en citaten worden hier alleen aangehaald om aan te geven dat het alternatief voor islamitisch onderwijs in Nederland niet zaligmakend is.

25 F.J. Buijs, 'Muslims in the Netherlands: Social and Political Developments after 9/11', Journal of Ethnic and Migration Studies 2009, p. 421-438; Entzinger \& Dourelijn 2008; J.R. Kunst e.a., 'Coping with Islamophobia: The effects of religious stigma on Muslim minorities' identity formation', International Journal of Intercultural Relations 2012, p. 518-532; A. Smeekes, M. Verkuyten \& E. Poppe, 'Mobilizing opposition towards Muslim immigrants: National identification and the representation of national history: Representations of national history', British Journal of Social Psychology 2011, p. 265-280; Z. Strabac \& O. Listhaug, 'Anti-Muslim prejudice in Europe: A multilevel analysis of survey data from 30 countries', Social Science Research 2008, p. 268-286; M. Verkuyten, 'Justifying discrimination against Muslim immigrants: Out-group ideology and the five-step social identity model: Justifying discrimination', British Journal of Social Psychology 2013, p. 345-360.

26 M.S. Merry, 'Indoctrination, Islamic schools, and the broader scope of harm', Theory and Research in Education 2018, p. 162-178; Merry \& Maussen 2018; M. Distelbrink \& T. Pels, 'Pedagogische ondersteuning en de spil-functie van het CJG', Pedagogiek 2012, p. 67-81; M. Zuidhof, “'Kinderen maken uitsluiting mee". Trees Pels over opvoeden in de multi-etnische stad', Zorg en Welzijn 2009, p. 1-4; M. Verkuyten \& J. Thijs, 'Racist victimization among children in The Netherlands: the effect of ethnic group and school', Ethnic and Racial Studies 2002, p. 310-331.

27 Fricker 2009; E. Goffman, Stigma: notities over de omgang met een geschonden identiteit, Utrecht 2018. 


\section{Emanciperende waarde van bijzonder onderwijs}

Voor critici van het bijzonder onderwijs is het soms moeilijk te geloven dat een school zowel de eigen identiteit van leerlingen kan versterken als kan bijdragen aan de integratie van deze leerlingen. Toch is dat wat op islamitische basisscholen gebeurt. Kinderen worden op een islamitische school weliswaar ingeleid in een religieuze traditie en gesterkt in een minderheidsidentiteit, maar gelijktijdig wordt vanuit de wens kinderen voor te bereiden op een toekomst in Nederland onderwijsinhoud behandeld die bij ouders gevoelig kan liggen. Het gevoel van geborgenheid waarin de scholen voorzien, maakt dat het onderwijs effectiever kan zijn. Paradoxaal genoeg stelt juist die religieuze segregatie leerkrachten in staat om gevoelige boodschappen met gepaste tact te kunnen brengen.

Het zou interessant zijn te onderzoeken of die emanciperende werking ook geldt voor andere bijzondere basisscholen in Nederland. Islamitische basisscholen hebben een bijna volledig religieus homogene schoolpopulatie, vergelijkbaar met bijvoorbeeld orthodox-joodse, hindoeïstische en gereformeerde/reformatorische basisscholen. Alle scholen zouden daarmee in staat moeten zijn om hun boodschap toe te spitsen op de specifieke religieuze doelgroep, en om 'gevoelige thema's' vast te stellen en onder de aandacht te brengen.

Bijzonder aan de situatie op islamitische basisscholen is dat die leerlingenpopulatie weliswaar in naam religieus homogeen is, maar vanwege haar etnische en nationale diversiteit toch te maken heeft met meningsverschillen over de interpretaties van de islam. Deze onderlinge diversiteit creëert een interne dialoog in de school en in de klas.

Concluderend kunnen we dus vaststellen dat de meeste islamitische basisscholen bijdragen aan de integratie van hun leerlingen in de Nederlandse samenleving, maar daaruit mogen we niet afleiden dat dat automatisch voor alle bijzondere confessionele scholen zou gelden. Niet zozeer het confessionele karakter van de islamitische school, maar de bijzondere bijkomende omstandigheden - zoals etnische diversiteit, interne dialoog, druk vanuit de samenleving - hebben ertoe geleid dat veel van deze scholen juist extra aandacht besteden aan integratie. Dat is gezien de maatschappelijke discussies over islamitisch onderwijs een belangwekkende observatie. 